\title{
Knowledge as Justified True Belief
}

\author{
Job de Grefte ${ }^{1}$ (D)
}

Received: 2 June 2020 / Accepted: 21 December 2020 / Published online: 19 February 2021

(c) The Author(s) 2021

\begin{abstract}
What is knowledge? I this paper I defend the claim that knowledge is justified true belief by arguing that, contrary to common belief, Gettier cases do not refute it. My defence will be of the anti-luck kind: I will argue that (1) Gettier cases necessarily involve veritic luck, and (2) that a plausible version of reliabilism excludes veritic luck. There is thus a prominent and plausible account of justification according to which Gettier cases do not feature justified beliefs, and therefore, do not present counterexamples to the tripartite analysis. I defend the account of justification against objections, and contrast my defence of the tripartite analysis to similar ones from the literature. I close by considering some implications of this way of thinking about justification and knowledge.
\end{abstract}

\section{Introduction}

What is knowledge? In this paper I defend the claim that knowledge is justified true belief. This account is well-known as the 'classical' or 'tripartite' analysis of knowledge. Many epistemologists, however, regard the claim to be plainly false. ${ }^{1}$ In this paper I aim to show that the tripartite analysis of knowledge should be given more credit than the current state of the debate affords it.

My defence will be indirect: I will argue that, on a plausible interpretation of the justification condition, Gettier cases do not present counterexamples to the tripartite analysis of knowledge. If successful, my argument shows that the tripartite analysis is more plausible than commonly supposed, not that it is beyond question.

The paper is structured as follows. In Sect. 2, I show that Gettier cases necessarily involve a kind of luck known as veritic luck. In Sect. 3, I provide a plausible

\footnotetext{
1 Indeed, the claim that knowledge is not justified true belief is one of the few philosophical claims David Lewis took to be established conclusively: "Philosophical theories are never refuted conclusively. (Or hardly ever. Gödel and Gettier may have done it)" (Lewis 1983, p. x).

Job de Grefte

j.a.m.de.grefte@rug.nl

1 Faculty of Philosophy, University of Groningen, Oude Boteringestraat 52, 9712 GL Groningen, The Netherlands
} 
interpretation of reliabilist justification that excludes veritic luck. In Sect. 4, I defend this interpretation against objections. In Sect. 5, I compare my defence of the tripartite analysis against alternatives from the literature. In Sect. 6, I consider some implications of the proposed way of thinking about justification and knowledge.

\section{Gettier Cases Involve Veritic Luck}

In this section I shall argue that Gettier cases necessarily involve a particular kind of luck: veritic luck. ${ }^{2}$

I will be working with a modal account of luck (MAL) (Pritchard 2005, 2014). According to this account, luck depends on the modal profile of an event: the distribution of possible worlds where the event does and does not occur. An event is a case of luck only if it occurs in the actual world, but fails to occur in (enough) nearby possible worlds, where, where a world is 'closer' to the actual world the more similar it is to it (Pritchard 2005, p. 128; Sainsbury 1997, p. 913). Nearby worlds represent 'easy' possibilities, since not much would need to change to the actual world for the event occurring in a nearby world to occur. On this interpretation, nothing is more easily possible than what happens in the actual world, since no world is closer (more similar) to the actual world than the actual world itself. The account correctly classifies paradigm cases of luck, like winning the lottery and finding a treasure, because such events could have easily failed to occur, in the sense that not much would need to change to the actual world for one to fail to win the lottery or fail to find the treasure.

Luck is relative both to a set of agents and to a set of 'initial conditions'. It is relative to agents because the same event may be lucky for one agent but not for another. The reason for this is that events need to be of some positive significance to some agent in order to be lucky: an avalanche on the South pole, no matter how easily it could have failed to occur, is not a case of luck if no one cares. ${ }^{3}$

Whether an event is a case of luck also depends on what we take to be its relevant initial conditions. For example, keeping fixed the complete state of the universe just prior to buying the ticket, my lottery win may well be fully determined, and therefore not a case of luck. However, fix only that I bought a random ticket, and under these conditions it will be easily possible for me to fail to win the lottery.

We arrive at the following definition of luck:

LUCK Event $\mathrm{E}$ is lucky for agent $\mathrm{S}$ under conditions I iff:

1. E is significant to $\mathrm{S}$ (or would be significant, were $\mathrm{S}$ to be availed of the relevant facts), and

2. E actually occurs, but could have easily failed to occur under conditions I.

\footnotetext{
${ }^{2}$ In other work, I investigate in some detail the nature of veritic luck (de Grefte 2018). Here, I will rest content with providing a brief overview of the main conclusions of that investigation.

3 In recent work, Pritchard drops such a significance condition on luck (Pritchard 2014). See (de Grefte 2019) for discussion.
} 
Veritic luck is a special kind of luck. It attaches to beliefs that are true but produced in a way that could have easily produced a false belief instead.

VERITIC LUCK: A belief is veritically lucky if and only if it is a matter of luck that the method one used to form one's belief produced a true belief. ${ }^{4}$

Suppose that I form a belief that the number of stars is even on the basis of a simple guess. My belief may be true. If it is, then it is veritically lucky, because it is produced in a way that could have easily resulted in me forming the false belief that the number of stars is uneven. ${ }^{5}$ As is common in the literature, I will assume that the formation of a true belief is of at least some significance to the relevant agents involved, and that the relevant initial conditions for veritic luck include the agent's method of belief formation. ${ }^{6}$

Why think that Gettier cases necessarily involve veritic luck? Consider one of Gettier's own cases (somewhat abbreviated for ease of use):

DISJUNCTION: Smith has excellent evidence for the proposition that Jones owns a Ford, and forms the corresponding belief. From this proposition, Smith competently deduces the further proposition that either Jones owns a Ford, or Brown is in Barcelona, and again forms the corresponding belief. Smith has no evidence whatsoever that indicates that Brown is in fact in Barcelona, and so formulates the second disjunct quite at random. Now suppose that through some elaborate deception, all Smith's evidence for believing that Jones owns a Ford is misleading, and Jones in fact does not own a Ford at all. Suppose further, however, that Brown is in Barcelona at the moment Smith forms his belief in the disjunction. His belief thus ends up being true.

It is widely accepted that in the above case Smith does not know that either Jones owns a Ford or Brown is in Barcelona. Note, however, that Smith's belief-forming method could have easily produced a false belief. For example, Smith could have easily formed the false belief that either Jones owns a Ford or Brown is in London. ${ }^{7}$ This Gettier case thus clearly involves veritic luck.

\footnotetext{
4 The definition of veritic luck that I am working with in this paper is different from those proposed by Pritchard (Pritchard 2005, 2014) and Engel (1992). Reasons for my alternative formation are given in full in (de Grefte 2018). Briefly put, the difference is that for Pritchard, in order to be veritically lucky, a belief must be produced by a method that easily produces that very same belief, but it would be false. The reason we opt for the present requirement is Pritchard's formulation renders beliefs in necessary truths necessarily non-lucky. For an objection along these lines see (Hales 2016). For a similar modification of Pritchard's account, see (Goldberg 2015, p. 274).

5 Here I assume that a guess whether p or not-p can easily result in either the belief that $\mathrm{p}$ or the belief that not-p.

6 The first of these assumptions is defended in (Whittington 2016). The second assumption is defended in (Pritchard 2005, Chapter 6).

7 As is well-known, it is difficult to specify adequate criteria for the individuation of methods of beliefformation (e.g. Conee and Feldman 1998). I believe this problem, known as the 'generality-problem' is an issue for any adequate theory of justification, and I will not attempt to solve it in this paper. Instead, I rely on an intuitive understanding of the methods involved in my examples.
} 
The above is just one example. Linda Zagzebski provides a general formula for generating Gettier cases (Zagzebski 1994). If we can show that, following this formula, one will be guaranteed to end up with a belief that is veritically lucky, this will suffice to show that all Gettier cases (at least of the standard sort covered by Zagzebski's formula) involve veritic luck.

Zagzebski's recipe is the following: take any non-factive epistemic condition you like and construct a case such that a given subject's true belief satisfies it. ${ }^{8}$ Then, modify the case such that accidentally, satisfying the epistemic condition does not lead you to form a true belief. Finally, make it so that as a second case of luck (unconnected to your cognitive activity), you end up with a true belief nonetheless (Zagzebski 1994, p. 66). In these cases, the subject will, according to Zagzebski, end up with a belief that satisfies the preferred conditions for knowledge, but will still fail to qualify as such. In short, the subject will end up with a Gettiered belief.

A belief is veritically lucky if one's belief-forming method actually produced a true belief but could have easily produced a false belief instead. In Gettier cases, according to Zagzebski, "an accident of bad luck is cancelled out by an accident of good luck. The right goal is reached, but only by chance" (Zagzebski 1994) Here the right goal is the formation of a true belief. It is reached by chance because one's method of belief formation is such that in the case at hand, it does nothing to lead you to form a true belief. In combination with the second kind of luck, this means not much would need to change to the actual world for the method to produce a false belief instead. Thus, it follows that all Gettier cases, or at least the ones that can be constructed using Zagzebski's method, will feature veritic luck. ${ }^{9}$

\section{A Modal Interpretation of Reliabilism}

In the previous section I argued that Gettier cases involve veritic luck. In this section and the next, I will defend the following claim:

JUSTIFICATION A belief is justified only if it is not veritically lucky.

The account is original in that anti-luck conditions are usually formulated as conditions on knowledge, rather than on justification (Littlejohn 2014; Pritchard 2005; Williamson 2009). Under the assumption that knowledge requires justification, our account will explain why there is such an anti-luck condition on knowledge. But depending on how these authors flesh out their notion of justification, our account may or may not be compatible with theirs. In any case, in this section I will argue specifically for an anti-luck condition on justification.

\footnotetext{
${ }^{8}$ A non-factive condition on belief is a condition such that satisfying the condition does not entail the truth of the belief. Accounts of justification that feature only non-factive conditions on justification are called fallibilist accounts of justification.

9 The claim that Gettier cases necessarily involve veritic luck is relatively uncontroversial (e.g. Engel 1992, p. 70; Pritchard 2005, p. 150). For some recent objections, see (Bernecker 2011; Hetherington 2011, Chapter 3).
} 
I will do so by first presenting a modal interpretation of Goldman's famous reliabilist theory of justification, an interpretation on which no justified belief is veritically lucky. While I believe many of Goldman's writings are compatible with such a reading of reliabilism, this is rarely noted, and the modal interpretation of reliabilism is not widely endorsed in the literature. I will therefore provide further support for this interpretation in the next section, by considering and diffusing main objections to it.

First, some preliminaries. The relevant kind of justification at issue in JUSTIFICATION is doxastic justification, a property of beliefs, rather than propositional justification, which is a property of propositions. ${ }^{10}$ Further, the claim specifies a necessary condition for doxastic justification, not a sufficient one. It may very well be that there are other necessary conditions on doxastic justification, besides the one proposed in this paper. It should finally be noted that whether a belief is veritically lucky depends on factors other than the believing agent's mental states or reflectively accessible information, so that the concept of justification we are working with here in this paper is externalist. ${ }^{11}$

JUSTIFICATION is supported by one of the most prominent accounts of doxastic justification in the literature: Goldman's process reliabilism $(1979,1994) .{ }^{12}$ While Goldman does not explicitly endorse the claim that justification excludes veritic luck in his writings, in this section I will argue that there is a plausible interpretation of his account that does.

Consider first Goldman's reliabilist account of justification:

RELIABILISM S's belief in p is justified IFF it is caused (or causally sustained) by a reliable cognitive process, or a history of reliable processes. (Goldman 1994)

The general idea behind reliabilism is that a belief is justified if and only if it is caused by a process that reliably produces true beliefs. Thus, beliefs formed on the basis of perception under normal circumstances will come out as justified (as they should) because under normal circumstances perception reliably causes true beliefs. Conversely, beliefs formed on the basis of tea-leaf reading will not come out as justified (as they should), because this process will not produce a high ratio of true over false belief.

There are different ways to understand the relevant truth/falsity ratio. First, we can understand it to concern actual operations of the process, or also counterfactual ones. This gives us the difference between frequency and modal interpretations of reliabilism. On a frequency account, what matters is whether the process in actual operation produces enough truth over falsity, whereas on the modal interpretation, what matters is whether the process would produce truth over falsity, even if it actually does not operate at all, or actually fails to produce enough truth over falsity.

\footnotetext{
10 For more on the distinction, see (Kornblith 2017; Silva and Oliveira forthcoming; Turri 2010).

11 We will come back to the relation between luck and the internalism/externalism debate in Sect. 6.

12 I provide a more brief argument for this claim in my (de Grefte 2018).
} 
We may further distinguish global from local reliability. A process is globally reliable if and only if it produces enough truth over falsity in all its possible or actual applications, whereas it is locally reliable if and only if it produces (or would produce) enough truth over falsity in situations similar enough to the actual case. Thus, 'going by eyesight' may be a globally reliable process or method, but it will not be a locally reliable method if one is currently in barn-façade county and forming beliefs about the presence of barns. Generally, (we presume,) trusting one's eyes will produce a high ratio of true beliefs over false ones, but in the context of barn-façade county, looks are deceiving, and so in similar circumstances one would form many false beliefs in the same way.

Which of these notions is relevant for justification? According to Timothy Williamson, reliability should be understood in modal rather than frequency terms:

Reliability and unreliability, stability and instability, safety and danger, robustness and fragility are modal states. They concern what could easily have happened. They depend on what happens under small variations in the initial conditions. (Williamson 2000)

In the epistemic context, there are good reasons for doing so, in particular that we would not want to say that belief-forming methods that are only used once are either completely reliable or completely unreliable. Relatedly, if I follow a version of the gambler's fallacy consistently, and believe that the next number of a roulette wheel will be the number that has not come up for the longest amount of runs, this method will not produce justified beliefs, even if in the actual circumstances in which I apply it, it actually does produce mostly true beliefs, What matters for justification seems to be whether the method could have easily produced false belief, not whether it has actually done so.

We can find a similar modal interpretation of reliability in the work of Goldman, specifically a local modal account, when he speaks about the reliability required for knowledge:

... a cognitive mechanism or process is reliable if it not only produces true beliefs in actual situations, but would produce true beliefs, or at least inhibit false beliefs, in relevant counterfactual situations. (Goldman 1976)

The reliability theories [of knowledge] presented above focus on modal reliability, on getting truth and avoiding error in possible worlds with specified relations to the actual one. They also focus on local reliability, that is, truthacquisition in scenarios linked to the specific scenario in question as opposed to truth-getting by a process or method over a wide range of cases. (Goldman and Beddor 2016)

At first sight, it is not clear whether the kind of reliability required for knowledge is the same as that required for justification according to Goldman. For example, in Epistemology and cognition, when he speaks explicitly about the reliability required for justification, Goldman again opts for modal condition, but one that is slightly more difficult to place on the global-local axis, since it makes the required reliability dependent on what happens in so-called 'normal' worlds-worlds that conform 
to our current beliefs about the world (1986, p. 107). Such 'normic' reliability conditions on justification receive support from recent defenses by Jarett Leplin and Martin Smith (Leplin 2009; Smith 2016).

Normic reliability resembles local reliability since both depend on what happens in a restricted class of worlds rather than all possible worlds. But it differs from local accounts of reliability in that it anchors the relevant set of worlds not to the actual world but to a class of 'normal worlds', where normal worlds are worlds compatible with our current beliefs about the world. Thus, if we are envatted brains, we may continue to believe as we do, and our methods would still be justified according to the normic reliability criterion (for these methods are reliable in worlds compatible with our current beliefs about the world). This is how normic reliabilists accommodate the intuition that the beliefs of BIV's are justified.

In this paper, I opt for a local conception of the kind of reliability required for justification rather than a normic conception. Normic accounts unduly prioritize the epistemic relevance of (our beliefs about) our current world. It is a guiding thought behind the present paper that methods that produce justified beliefs do so because they ensure a proper fit between our beliefs and the world. If the notion of reliability has any relevance in epistemology it is to designate that our methods are guides to truth. That some method is reliable in contexts in which it will never be used seems of little epistemic relevance. Normic reliability accounts predict that BIV's are justified in using our empirical belief-forming methods even if the relevant subject is envatted from the moment they are born to the moment they die, and these empirical methods never produce a single true belief. Ideally, we want a general analysis that has sensible conditions on knowledge and justification not just for us, but for creatures cognizing in vastly different epistemic contexts as well. It is hard to imagine why such creatures would accord any epistemic relevance to methods that are reliable at our world only. What their epistemologists would care about is reliability in their context, and so I think it is local reliability that ultimately matters for a general theory of justification.

In any case, Goldman abandoned his normic account in favor of a distinction between strong and weak justification (Goldman 1988). A belief is said to be strongly justified just in case it is produced by an (epistemically) adequate method, whereas it is said to be weakly justified just in case the believer is (epistemically) blameless in so believing. Since no method for which one is epistemically to blame is epistemically adequate, strong justification implies weak justification, but not the other way around, for adequate methods may require more than just blameless believing.

What more is required? Here Goldman is very explicit. For any belief-forming process, we should assess its "rightness [strong justification] in [world] W not simply by its performance in $\mathrm{W}$, but by its performance in a set of worlds very close to W" (Goldman 1988, p. 63). This clearly indicates that the reliability that Goldman thinks is required for strong justification is local modal reliability.

The same kind of reliability is not required for weak justification, however, as becomes clear from Goldman's treatment of the Cartesian demon case (a variant of the envatted brain case discussed above): "The present version of reliabilism accommodates the intuition that demon-world believers have justified beliefs by granting 
that they have weakly justified beliefs" (Goldman 1988, pp. 62, 63). Obviously, demon-world victims do not have beliefs that are produced by processes that perform well in their actual world as well as in a set of worlds close to the demonworld. This does not stop their beliefs from being weakly justified according to Goldman, so weak justification does not require local modal reliability.

Weak justification thus does not eliminate veritic luck. But with our definitions of veritic luck and local modal reliability in hand, it is easy to see that strong justification, as well as any account that requires local modal reliability, does entail the absence of veritic luck.

First, a method that is locally modally reliable is a process or method that produces a high ratio of truth over falsity situations similar to the actual case. Second, a belief is veritically lucky if and only if the method or process that produced it produced a true belief but produces false belief in close possible worlds.

Now, it is natural to interpret the notion of 'similar circumstances' occurring in our definition of local modal reliability in terms of close possible worlds. After all, close possible worlds are defined as worlds that differ little from the actual world. Such an interpretation of reliabilist justification fits well with Goldman's claims regarding the modal profile of strong justification provided above, as well as with his treatment of BIV's. Envatted subjects lack reliably formed beliefs because in worlds close to their actual world, their methods produce false beliefs too often. We will thus continue under the assumption that the notions of 'close possible worlds' and 'similar situations', as they occur in the definitions of veritic luck and local modal reliability, share their extension.

Admittedly, it is unclear how 'wide' the class of worlds where the agent forms a false belief in the same way as she formed her true belief in the actual world must be for a belief to count as veritically lucky. ${ }^{13}$ But similarly, it is unclear what counts as a similar situation, on a local modal reliabilist conception of justification.

To circumvent this worry, I will assume that reliability and veritic luck are both graded notions. By this I mean that our beliefs can be more or less reliable than other beliefs, without it being clear that there is a sharp cut-off point between reliable and unreliable beliefs. The same holds for veritic luck: it is intuitively plausible that there is a continuum of veritic luck, where beliefs can be more, or less veritically lucky without there being a precise cut-off point where a veritically lucky belief becomes a non-veritically lucky one.

If this is true, then it follows that the higher the local modal reliability of a method is, the lower the degree of veritic luck will be that attaches to the beliefs produced by this method. In this sense, a local modal reliability condition behaves as an anti-veritic luck condition on justification. The more (locally modally) reliable your method, the less subject your beliefs are to veritic luck. In the extreme case, complete local modal reliability entails complete absence of veritic luck (in this case, there are no nearby possible worlds where one's method produces a false belief).

\footnotetext{
13 Pritchard does go into this issue when he talks about the related notion of safety (Pritchard 2005, Sects. 6.2-6.4).
} 
A final point worth emphasizing in this section is that while RELIABILISM takes reliability to be both necessary and sufficient for justification, I will commit myself only to its necessity (that is why JUSTIFICATION does not feature a biconditional). There are several reasons for this, some will be outlined in the next section, and some in Sect. 6. But perhaps the most important point presently is that I want to show as clearly as possible what is required to evade Gettier cases, and an anti-veritic luck condition on justification suffices for this purpose. Perhaps other conditions on justification are necessary, perhaps not. We will leave this question for another time.

Let us briefly recap. I have presented in this section a local modal interpretation of RELIABILISM supported by the writings of Alvin Goldman, and argues that it excludes veritic luck. This means that there is at least one prominent and plausible account of justification in the literature that satisfies JUSTIFICATION. I do not claim the interpretation presented in this section is the only possible interpretation of RELIABILISM, nor that it is Goldman's own interpretation, nor that RELIABILISM is the only plausible account that satisfies JUSITIFICATION. My aim in this paper is only to establish that there is a plausible interpretation of justification that allows for an anti-luck defense of the tripartite analysis of knowledge, not that this defense is possible for all accounts of justification. In the next section I will provide further support for JUSTIFICATION by defending it against objections.

\section{Lotteries, Evil Demons and Other Objections}

While I have argued in the previous section that there is at least one prominent and plausible account that satisfies JUSTIFICATION, such an condition on justification is not widely endorsed in the literature. In this section I will review and respond to some possible objections.

First, I suspect some will find an anti-veritic luck condition too strong on the basis of how the account handles lottery cases. Instead, a probabilistic interpretation of RELIABILISM may be preferrable. In lottery cases, purely on the basis of the long odds involved, you form the (true) belief that the lottery ticket you just bought will lose. Forming your belief in this way will result in error in nearby worlds, since any of the tickets, including yours, could easily be drawn. If this much is admitted, then your belief is subject to at least some veritic luck, and our account seems to rule it as unjustified. This may strike some as counterintuitive. After all, the probability that your ticket is drawn is extremely small, given a large enough lottery. Thus, on this basis, one may prefer a probabilistic conception of RELIABILISM, where your belief is produced reliably just in case the probability of forming a false belief is small enough. In lottery cases, such a condition would be satisfied, which would allow proponents of such a reliabilism to say that lottery beliefs are justified.

In response, I would like to say the following things. First, it is not as clear cut as it may initially seem that lottery beliefs are justified. For example, some authors have argued for a knowledge norm on justification, and since it is universally accepted that we cannot know that our ticket will win on the basis of the odds alone, these views entail that lottery beliefs are not justified (Sutton 2005). Others have adduced 
other externalist conditions on justification that seem to rule out lottery beliefs from counting as justified (Littlejohn 2014; Smith forthcoming, 2016). In denying justification to lottery beliefs, I would not be alone.

Of course, it is better to provide a principled reason for denying justification in lottery cases. Our account provides such a reason: lottery beliefs are produced by a method that could have easily produced a false belief, and such methods fail to provide justification. This requires that the notion of easy possibility is given a modal characterization, but such interpretations have been fruitfully applied in philosophy at least since Lewis' analysis of counterfactuals (Lewis 1973).

If one is not convinced, our verdict can be made more palatable by noting again that justification is a matter of degree. While JUSTIFICATION entails that lottery beliefs are not completely justified, since there are some nearby possibilities for error, our account is compatible with the idea that such beliefs still receive a relatively high degree of justification, since there are only a few such nearby errorpossibilities. The only thing entailed by JUSTIFICATION is that lottery beliefs are not completely justified, but this same verdict must be reached by a probabilistic reliabilist. I conclude that lottery cases do not pose a serious threat to our account. ${ }^{14}$

Let us move on to the next set of objections, both derived from Chris Kelp (2017). Kelp provides an alternative competence-based version of RELIABILISM, where (roughly) a belief is justified if and only if it is formed by an ability to form true beliefs. By providing both necessary and sufficient conditions on justification, Kelp's account of justification is more ambitious than the present view, which commits itself to a necessary condition only.

In his paper, Kelp discusses two problems that may threaten JUSTIFICATION. ${ }^{15}$ The first concerns new evil demon cases. Accounts like ours deny

\footnotetext{
${ }^{14}$ It is worthwhile to pause on the distinction between partial and complete justification. In this paper, I argue that the tripartite account of knowledge can be saved from Gettier-style counterexamples by positing an anti-luck condition on justification. As I have shown above, Gettier cases necessarily involve veritic luck. But luck comes in degrees, so our beliefs may be subject to more or less veritic luck, The degree of veritic luck present in Gettier cases, is assumed to be high enough to destroy knowledge. But it is a further question, one not often explicitly dealt with in the literature, whether any degree of veritic luck is incompatible with knowledge. Lottery cases may be marshalled in support of the view that knowledge requires the absence of even low degrees of veritic luck, since, while the nearest possible world where one forms a false belief on the basis of the same method is close (just a few different numbers have to come up), but the proportion of nearby worlds where one forms a false belief on the basis of employing the same methods is arbitrarily small. Some veritic luck is involved, but not very much, it seems. The widespread intuition that lottery propositions are not known provides some evidence that knowledge is incompatible with even very small degrees of veritic luck. For the larger project of this paper this issue can be left undecided. To save the tripartite analysis, we only need to assume that knowledge is incompatible with the degree of veritic luck present in Gettier cases, and then argue that justification is incompatible with the same degree of veritic luck. This is what I have aimed to do in Sect. 3. It should be noted, however, that our account is flexible enough to accommodate the thought that knowledge requires the complete absence of veritic luck, but that I am not committed to an account of justification that eliminates veritic luck completely. This issue will come up again in Sect. 6.

${ }^{15}$ Kelp discusses two other problems: clairvoyant cases and the generality problem. I will set the generality problem aside here, since this is a problem not specific to the present account (Bishop 2010), and would in any case require much more discussion. Clairvoyant cases are irrelevant in the present discussion because they seem to contradict the sufficiency of reliability for justification, a claim not endorsed in this paper.
} 
justification in such cases, since they feature beliefs that, if true at all, are subject to substantial degrees of veritic luck. Kelp maintains our verdict in these cases is implausible. In response, we have already argued against normic accounts of reliabilism that there are reasons to suppose victims in such deception cases lack justified beliefs, so I am prepared to bite this bullet. Moreover, Kelp's own account of justification falls prey to a generalized version of the New Evil Demon case. Let us see why. Kelp evades standard new evil demon cases because according to Kelp, such cases involve conditions $\mathrm{C}$ "highly unsuitable for your ability to form true beliefs about the time in the sense that using $\mathrm{W}$ [your way of forming beliefs] in C does not dispose you to form true beliefs" (Kelp 2017, p. 19). In standard new evil demon cases, however, $\mathrm{W}$ is grounded in normal conditions $\mathrm{C}$ ' (say, regular conditions as we take them to be on earth), in which exercising W does lead to true belief. So even in the demon case, you still form your beliefs by exercising an ability to form true beliefs, and so it seems that Kelp can accommodate the intuition that victims of radical deception are justified in their beliefs.

The case may be generalized, however, such that you are radically deceived since you were born. In such a case, your ability cannot be grounded in circumstances where you are disposed to form true beliefs (because you have never been able to form true beliefs about your environment). In this case, Kelp would have to agree that the relevant beliefs are unjustified. This puts our accounts in the same boat in this respect. To the extent that BIV's and evil demon scenario's count against our account, our generalized scenario should count against Kelp's account as well. As said, however, I think the best way to respond to such scenarios is to bite the bullet. Whether our belief-forming methods provide us with justified beliefs depends on whether they are reliable guides to truth, and our present ways of forming our beliefs fail this criterion in radical deception cases.

The last objection I want to discuss concerns the kind of reliabilism I used in the previous section to support JUSTIFICATION. Kelp objects to standard process-reliabilist theories of justification that their measure of reliability depends on truth-falsity ratios at worlds. An account based on competences is better, according to Kelp, because competences are defined relative to conditions (you may competently play the piano, but not underwater). Kelp provides an example where people are generally unable to tell chantarelles from jack-of-lanterns, a very similar looking mushroom. Since chantarelles are edible but jack-of-lanterns are not, people cannot reliably tell whether a mushroom with the relevant appearance is edible, so their beliefs about this will not be justified on standard reliabilist accounts. Now imagine a secluded island where there are only chantarelles around. In this case, Kelp argues, we want to say that the beliefs of people living there about the edibility of these mushrooms are justified. His account predicts 
that they are, since in so believing they exercise an ability to believe truly. Reliabilism does not seem to deliver this verdict, because even if in their local context the beliefs are reliable, the kind of reliability adduced by standard process-reliabilism is defined over the whole world, which means, given the above, that their method is unreliable.

I want to grant Kelp the point against the standard kind of process-reliabilism that he discusses. But as we have made clear above, the general reliabilist framework is flexible enough to accommodate other measures of reliability than the one discussed by Kelp. In particular, we have been working with a local modal conception of reliability, which concerns reliability in cases similar to the actual case. Take any instance of a belief about the edibility of one of the chantarelles formed by someone living on the island described above. Does this way of forming their beliefs produce error in close possible worlds? Assuming that the person never leaves the island, it seems hard to deny that their method is locally modally reliable; quite a lot would have to change for this way of forming their beliefs to produce false belief here. Of course, that will change if one introduces jack-of-lanterns into the case, but the more of those we stipulate there to be on the island, the less strong our inclination to attribute justification, just as local modal reliabilism predicts.

All in all, our defense of JUSTIFICATION stands up to the challenges discussed above. Lottery beliefs may be justified to a high degree but are not completely justified. Beliefs of radically deceived agents do not seem to be justified at all. The final objection discussed emphasizes the plausibility of the local modal reliabilism used in the previous section to support JUSTIFICATION. The point of all this is to support the tripartite analysis of knowledge. In this next section, we compare our strategy to some recent alternatives.

\section{Similar Strategies}

I have argued that we can save the traditional analysis of knowledge against Gettier's famous counterexamples if we properly understand what is required for justification. In different ways, Adrian Haddock and Mark Schoeder have argued for similar points (Haddock 2010; Schroeder 2015b). ${ }^{16}$ In this section, I will compare my account to theirs and provide some reasons for preferring the present one.

Let us address these accounts in alphabetical order. According to Adrian Haddock, knowledge is justified true belief where the justification condition is factive (one cannot justifiably believe that $p$ when $p$ is false) and requires moreover that the fact that provides justification is known by the subject. Haddock restricts his discussion to the case of visual knowledge, in which case, he argues, the fact that provides

\footnotetext{
${ }^{16}$ Schroeder does not intend to save the tripartite analysis, since his account of knowledge features a fourth condition on knowledge (that the relevant belief is supported by sufficient objective reason). However, since he clearly aims to provide an analysis of knowledge, it is still worthwhile to compare the account to ours.
} 
justification is 'that one sees that $p$ '. Since both knowledge and seeing are factive states, it is impossible to be justified in this sense without it being the case that $p .{ }^{17}$

We need not delve into the details of Haddocks account to note two main differences between it and the account presented in this paper. First, I do not consider justification to be a factive state in general. While complete justification may require the absence of false belief in nearby worlds, including our actual one, lesser degrees of justification do not, and are compatible with some false beliefs in nearby worlds, including our own. So, we can believe with a high degree of justification, on our present account, without it being the case that our belief is true. Secondly, I do not require the kind of second-order knowledge that Haddock requires for a belief to be justified. I suspect such a requirement is too strong, lest children, animals, and even probably most adult humans lack much of the knowledge we think they have. Rarely do we form beliefs about what justifies our beliefs, and when we do, such beliefs may simply be wrong, as the literature on cognitive bias makes painfully clear. Yet, as long as the methods we use to form the relevant beliefs are reliable enough, in our specific sense of local modal reliability, they may on our account amount to knowledge nonetheless. On our account knowing things about the world is a matter of having proper epistemic access to that world, and not of having proper second-order beliefs about the kind of access we enjoy.

Schroeder defines knowledge as belief for sufficient subjective and objective reason (Schroeder 2015b). We will again focus on the case of visual knowledge. In cases of normal perception, you look at an object (say a dog) and form the belief that there is a dog over yonder. In such cases, according to Schroeder, your evidence is that you see that there is a dog over yonder. If you properly base your belief on this reason, it will count as subjectively sufficient (the fact that seeing is a factive state rationalizes your belief that there is a dog over yonder). If it is also true that you see that there is a dog over yonder (which for Schroeder means that there is no deception going on), then you also believe for objectively sufficient reason, and your belief may then amount to knowledge.

Schroeder is explicit in saying that doxastic justification for him requires believing for sufficient subjective reason only. This entails, among other things, that subjects' beliefs in fake barn cases are doxastically justified on Schroeder's account. Regarding a subject located in Fake Barn country, Schroeder says:

[S]he knows just in case the reasons for which she believes are both objectively and subjectively sufficient. And according to my take on the Kantian account [Schroeder's account], her belief is doxastically rational just in case

\footnotetext{
17 Haddock's account of justification is not the only factive account of justification. Views that equate justification with knowledge, such as Sutton's (2005) account, will entail that justification is factive. Also, disjunctivist accounts of perceptual knowledge such as McDowell's (2009) may entail that justification (at least conceived of as the warrant required for knowledge) is factive. It is not possible here to compare my account to all alternatives. The decision to focus on the accounts of Haddock and Schroeder is motivated by the fact that both of them seem to be concerned explicitly with the analysis of knowledge. Since this is also my project here, the comparison between these different strategies is especially relevant.
} 
her reasons are subjectively sufficient. So given that the agent in the fake barn case believes rationally, the Kantian Account can deny that she knows only if it turns out that her reasons are not objectively sufficient. (Schroeder 2015a, p. 377)

Schroeder's analysis of such cases thus seems to be one of doxastic justification but failure of knowledge because the subject's subjectively sufficient reason is not also objectively sufficient. As an attempt to save the tripartite analysis, this strategy fails: we have here a case of doxastically justified true belief that nevertheless fails to amount to knowledge. The account also clearly conflicts with our present proposal, since on our account subjects in fake barn country do not know because they are not justified. In such cases, one's method may all to easily produce false belief, such as when one is looking at a fake barn, and so one is not justified to believe there is a barn over yonder even if one is looking at the one real example.

Fake barn cases are controversial, but I think intuitions to the effect that fake-barn beliefs are justified can be explained away by noting that the same way of forming our beliefs about barns in the distance is presumably, in most of the contexts where we find ourselves, a locally modally reliable method. We don't usually go wrong by using this method, we assume. And so, we conclude that using the method provides justification tout court. However, the point of requiring local modal reliability for justification is that it is plausible that whether a belief-forming method provides justification may differ across contexts. A method fit for forming true beliefs in one environment may not be so helpful in others. And in fake barn cases, going by eyesight errs too easily for that method to provide justification.

Thus, the approaches of Haddock and Schroeder are substantially different from the present one, which, I have argued, is to be preferred.

\section{Further Implications}

So far, I have argued that Gettier cases necessarily involve veritic luck, and that a local modal interpretation of RELIABILISM entails that justified beliefs cannot be veritically lucky. Together, these claims entail that no Gettier case can involve justified beliefs, and thus, that they do not provide counterexamples to the tripartite account of knowledge. ${ }^{18}$ I have defended the account against objections and alternative analyses of knowledge. In this section, I discuss some implications of the present anti-luck approach to justification.

First, Linda Zagzebski has famously argued that Gettier cases are inescapable, in the sense that no non-factive account of justification immune to Gettier cases can be formulated (Zagzebski 1994). Since she explicitly discusses reliabilist conditions on justification, her findings may seem conflict with our claim that local modal reliabilism evades such cases. This impression would be incorrect, however, as Zagzebski

\footnotetext{
18 This defence of the tripartite account is indirect because it concerns the removal of one of the main arguments against the tripartite account.
} 
is working with a probabilistic version of reliabilism, not a local modal one. Since I acknowledge that probabilistic versions of reliabilism will not suffice to rule out veritic luck, Zagzebski's claim that reliabilism does not rule out veritic luck, properly understood, is compatible with what is argued here.

Zagzebski, however, further argues that no non-factive account of justification (where a factive account of justification is an account that entails justified beliefs are true) is going to be immune to Gettier cases. ${ }^{19}$ As I have argued above, our general account of justification is non-factive. Justification comes in degrees. One's belief is completely justified if there are no nearby possible worlds where one forms a false belief. Since the actual world counts as near to itself, it is not possible to be completely justified when one believes falsely. So, complete justification is factive on the present picture. But one may be justified to a lesser degree. In this case, the higher the proportion of nearby possible worlds where one forms a false belief, the lower one's degree of justification. Since lower degrees of allow for false belief in nearby worlds, including the actual world, our general account of justification is non-factive.

It is a further question whether degrees of justification lower than complete justification suffice to rule out knowledge-undermining luck, and thus, in effect, whether knowledge requires complete justification on our account. I am inclined to think that knowledge may be compatible with minute amounts of veritic luck, given our frequent knowledge attributions. Officially, however, I will leave this as an open question. Knowledge may require complete justification (in which case the truth condition in the tripartite analysis is superfluous), or it may only require a lesser degree of justification (in which case the truth condition is required, and in which case our account provides a counterexample to Zagzebski's claim). ${ }^{20}$ Perhaps, as some have argued, the standards for knowledge depend on context, such that in some contexts, stronger justification is required than in others (Stanley 2005). Full discussion of this point will have to wait for another time; our account is flexible enough to handle any of the potential outcomes.

Let us return to our main line of argument. In this paper, I argued that there is a plausible account of justification where Gettier cases do not undermine the claim that knowledge is justified true belief. Why then, do so many epistemologists consider the tripartite analysis refuted?

\footnotetext{
19 Zagzebski's claim is relatively easily refuted. Suppose one posits that the absence of veritic luck is both necessary and sufficient for justification. Such an account is non-factive and able to evade Gettier cases. The arguments for the latter part of this claim have been provided above. Further, such an account would not be factive because a belief is veritically lucky only if it is both true and produced by a method that could easily have produced a false belief. False beliefs fail the first conjunct and so, on this account, cannot be veritically lucky. So, an account that posits that the absence of veritic luck is both necessary and sufficient is non-factive and immune to Gettier cases.

20 More recently, Zagzebski seems to admit as much when she discusses the lesson to be drawn from Gettier (Zagzebski 2017). While she thinks anti-luck approaches like the one from Howard-Snyder, Howard-Snyder and Feit (2003) are immune to Gettier cases, she thinks such accounts are 'uninteresting' and 'ad-hoc'. Since these issues are not our central concern here, we will set them aside.
} 
The answer seems to be that before Gettier, justification is generally given an internalist gloss. ${ }^{21}$ Because such accounts tend to be compatible with justified beliefs that are produced by methods that could very easily have produced false belief (BIV-beliefs, demon beliefs, etc.), such accounts will not eliminate veritic luck. $^{22}$ It is for this reason that Ted Poston, for example, writes: "[s]tandard Gettier cases show that one can have internally adequate justification without knowledge" (2016, my emphasis). It is because our anti-luck condition is an externalist condition that it evades Gettier-cases.

Interestingly, internalist justification is incompatible with a different kind of luck:

REFLECTIVE LUCK S's belief that $p$ is reflectively lucky if and only if, given the information reflectively accessible to $S$, it is a matter of luck that the method $\mathrm{S}$ used to form her belief that p produced a true belief.

Note the parallels between veritic and reflective luck. Whereas veritic luck requires the belief to be true but produced by a method that could have easily produced false belief instead, the notion of reflective luck requires this same thing to be the case, but then judged from one's reflective perspective. ${ }^{23}$ Some examples of reflectively lucky beliefs include beliefs formed on the basis of simple guessing and the beliefs of Brandom's famous chicken-sexers, or Bonjour's equally famous clairvoyant (BonJour 1980; Brandom 1998). It is important to note that beliefs can be reflectively lucky without being veritically lucky (as is the case in the latter two examples mentioned above). Even if the chicken-sexer from her own perspective cannot explain why she reliably forms true belief, her method still is locally modally reliable. Similarly, beliefs can also be veritically lucky without being reflectively lucky, as when things look as if one's method is a (locally modally) reliable one, whereas in fact it is not.

With the distinction between reflective and veritic luck in hand, it is possible to draw an alternative lesson from Gettier. The primary target of internalist concepts of justification is the elimination of reflective, not veritic luck. What Gettier showed us, is that there is another kind of luck that prevents knowledge: veritic luck. Since Gettier's paper predates the careful distinctions of anti-luck epistemology, this point remains entirely implicit. ${ }^{24}$

Still, I submit this is the main lesson from Gettier. It explains why Gettier cases are seen to refute the tripartite analysis of knowledge: because traditional accounts of justification aim to eliminate reflective but not veritic luck, the conditions laid

\footnotetext{
${ }^{21}$ For some examples, see the theories explicitly targeted by Gettier: those of Chisholm $(1957$, p. 16) and Ayer (1956, p. 34).

22 See my (de Grefte 2018).

23 The notion of reflective luck is derived from Duncan Pritchard's seminal work on epistemic luck (Pritchard 2005). Note that our account differs slightly from Pritchard's account, just like our account of veritic luck differs slightly from Pritchard's version in the same way as our account of veritic luck in order to avoid necessarily true propositions to be immune from reflective luck.

24 Note that I am not saying here that Gettier intended his cases to be read in this way. I am merely speculating that this is the best way to make sense of the cases, and the lesson to be drawn from them.
} 
down by these accounts can be satisfied even in the presence of veritic luck, which opens the door to Gettier cases.

The main lesson from Gettier is not that knowledge is incompatible with luck simpliciter, but specifically that knowledge is incompatible with veritic luck. A next question is then what this means for the analysis of knowledge. The overwhelming majority opinion is that Gettier refuted the classical, tripartite account of knowledge. But our present findings open up the possibility for a different interpretation. As I have been arguing in this paper, a plausible reading of reliabilist justification requires the elimination of veritic luck. On this account, Gettier cases lose their teeth. $^{25}$

\section{Conclusion}

Let us conclude. In this paper I have argued that by focussing on the relation between epistemic justification and luck, we can defend the traditional analysis of knowledge as justified, true, belief. Gettier cases are usually seen to refute any such attempt, but we have seen that all Gettier cases involve veritic luck, and that a plausible version of reliabilism about epistemic justification eliminates veritic luck. If this is so, then no belief in Gettier cases is epistemically justified, properly understood. That means that Gettier cases lose their teeth, and we can consistently maintain the claim that knowledge is justified true belief even in the light of any failure to know in Gettier cases.

Acknowledgements I would like to thank Alvin Goldman for helpful disccussion of this material, as well as the audience from the OZSW Conference 2019 in Amsterdam, and two anonymous referees for this journal.

Open Access This article is licensed under a Creative Commons Attribution 4.0 International License, which permits use, sharing, adaptation, distribution and reproduction in any medium or format, as long as you give appropriate credit to the original author(s) and the source, provide a link to the Creative Commons licence, and indicate if changes were made. The images or other third party material in this article are included in the article's Creative Commons licence, unless indicated otherwise in a credit line to the material. If material is not included in the article's Creative Commons licence and your intended use is not permitted by statutory regulation or exceeds the permitted use, you will need to obtain permission directly from the copyright holder. To view a copy of this licence, visit http://creativecommons.org/licen ses/by/4.0/.

\footnotetext{
$\overline{{ }^{25}}$ One note in closing, however. In modifying their justification conditions, externalists usually propose conditions that do not require the elimination of reflective luck. But it is perfectly consistent to require that justification requires both the absence of veritic, and of reflective luck. Prima facie, such an account of justification would seem to satisfy important externalist as well as internalist intuitions about justification. This is a theoretical possibility that is often overlooked in the debate between internalists and externalists, perhaps because externalism is often formulated as the explicit denial of internalism. Ernest Sosa is among the few epistemologists that have long stressed the importance of both externalist and internalist justification, at least when the higher grades of knowledge are concerned (2009, 2010). Duncan Pritchard notes the compatibility but remains uncommitted toward such a hybrid account of justification (2005, Chapters 6, 7, 8). A hybrid approach also seems compatible with Goldman's distinction between strong and weak justification (Goldman 1988).
} 


\section{References}

Ayer, A. J. (1956). The problem of knowledge (Vol. 8). Harmondsworth: Penguin books.

Bernecker, S. (2011). Keeping track of the Gettier problem. Pacific Philosophical Quarterly, 92(2), 127-152.

Bishop, M. A. (2010). Why the generality problem is everybody's problem. Philosophical Studies: An International Journal for Philosophy in the Analytic Tradition, 151(2), 285-298.

BonJour, L. (1980). Externalist theories of empirical knowledge. Midwest Studies in Philosophy, 5(1), 53-73.

Brandom, R. (1998). Insights and blindspots of reliabilism. The Monist, 81(3), 371-392.

Chisholm, R. M. (1957). Perceiving: A philosophical study (Vol. 9). Ithaca: Cornell University Press.

Conee, E., \& Feldman, R. (1998). The generality problem for reliabilism. Philosophical Studies, 89(1), $1-29$.

de Grefte, J. (2018). Epistemic justification and epistemic luck. Synthese, 195(9), 3821-3836.

de Grefte, J. (2019). Pritchard Versus Pritchard on Luck. Metaphilosophy, 50(1-2), 3-15.

Engel, M. (1992). Is epistemic luck compatible with knowledge? The Southern Journal of Philosophy, $30(2), 59-75$.

Goldberg, S. C. (2015). Epistemic entitlement and luck. Philosophy and Phenomenological Research, 91(2), 273-302.

Goldman, A. I. (1976). Discrimination and perceptual knowledge. The Journal of Philosophy, 73(20), $771-791$.

Goldman, A. I. (1979). What is justified belief? In G. S. Pappas (Ed.), Justification and knowledge (pp. 1-23). Dordrecht: D. Reidel Publishing Company.

Goldman, A. I. (1986). Epistemology and cognition. Cambridge, MA: Harvard University Press.

Goldman, A. I. (1988). Strong and weak justification. Philosophical Perspectives, 2, 51-69.

Goldman, A. I. (1994). Naturalistic epistemology and reliabilism. Midwest Studies in Philosophy, 19, 301-320.

Goldman, A. I., \& Beddor, B. (2016). Reliabilist epistemology. In E. N. Zalta (Ed.), Stanford encyclopedia of philosophy (winter 201). Stanford: Metaphysics Research Lab, Stanford University.

Haddock, A. (2010). Knowledge and justification. In the nature and value of knowledge. Oxford: Oxford University Press.

Hales, S. D. (2016). Why every theory of luck is wrong. Noûs, 50(3), 490-508.

Hetherington, S. C. (2011). How to know: A practicalist conception of knowledge. Hoboken: Wiley.

Howard-snyder, D., Howard-snyder, F., \& Feit, N. (2003). Infallibilism and Gettier's legacy. Philosophy and Phenomenological Research, 66(2), 304-327.

Kelp, C. (2017). How to be a reliabilist. Philosophy and Phenomenological Research, 98, 1-29.

Kornblith, H. (2017). Doxastic justification is fundamental. Philosophical Topics, 45(1), 63-80.

Leplin, J. (2009). A theory of epistemic justification. Berlin: Springer.

Lewis, D. K. (1973). Counterfactuals. Cambridge, MA: Harvard University Press.

Lewis, D. K. (1983). Philosophical papers (Vol. 1). New York: Oxford University Press.

Littlejohn, C. (2014). Fake barns and false dilemmas. Episteme, 11(4), 369-389.

McDowell, J. (2009). Selections from criteria, defeasibility, and knowledge. In A. Byrne \& H. Logue (Eds.), Disjunctivism: Contemporary readings (pp. 75-91). Cambridge: MIT Press.

Poston, T. (2016). Internalism and externalism in epistemology. Philosophical Topics, 14(1), 179-221.

Pritchard, D. (2005). Epistemic luck. New York, NY: Oxford University Press.

Pritchard, D. (2014). The modal account of luck. Metaphilosophy, 45(4-5), 594-619.

Sainsbury, M. R. (1997). Easy possibilities. Philosophy and Phenomenological Research, 57(4), 907-919.

Schroeder, M. (2015a). In defense of the Kantian account of knowledge: Reply to Whiting. Logos \& Episteme, 6(3), 371-382.

Schroeder, M. (2015b). Knowledge is belief for sufficient (objective and subjective) reason. In T. S. Gendler \& J. Hawthorne (Eds.), Oxford studies in epistemology (Vol. 5, pp. 226-252). Oxford: Oxford University Press.

Silva, P., \& Oliveira, L. R. G. (forthcoming). Propositional justification and doxastic justification. In M. Lasonen-Aarnio \& C. M. Littlejohn (Eds.), Routledge handbook of the philosophy evidence. Abingdon: Routledge. 
Smith, M. (2016). Between probability and certainty: What justifies belief. Oxford: Oxford University Press.

Smith, M. (forthcoming). Four arguments for denying that lottery beliefs are justified. In I. Douven (ed.), Lotteries, knowledge and rational belief: Essays on the lottery paradox. Cambridge: Cambridge University Press.

Sosa, E. (2009). Reflective knowledge: Apt belief and reflective knowledge (Vol. II). Oxford: Oxford University Press.

Sosa, E. (2010). Knowing full well. In knowing full well. Princeton, NJ: Princeton University Press.

Stanley, J. (2005). Knowledge and practical interests. Oxford: Oxford University Press.

Sutton, J. (2005). Stick to what you know. Nous, 39(3), 359-396.

Turri, J. (2010). On the relationship between propositional and doxastic justification. Philosophy and Phenomenological Research, 80(2), 312-326.

Whittington, L. J. (2016). Luck, knowledge and value. Synthese, 193(6), 1615-1633.

Williamson, T. (2000). Knowledge and its limits. Oxford, NY: Oxford University Press.

Williamson, T. (2009). Probability and danger. The Amherst Lecture in Philosophy, 4, 1-35.

Zagzebski, L. (1994). The inescapability of Gettier problems. Philosophical Quarterly, 44(174), 65-73.

Zagzebski, L. (2017). The lesson of gettier. In explaining knowledge. Oxford: Oxford University Press.

Publisher's Note Springer Nature remains neutral with regard to jurisdictional claims in published maps and institutional affiliations. 